TECHNICAL NOTE

\title{
Fragility of Hydraulic Elevators for Use in Performance-Based Earthquake Engineering
}

\author{
Keith Porter, ${ }^{\text {a) }}$ M.EERI
}

New performance-based earthquake engineering methods developed by the Pacific Earthquake Engineering Research Center, the Applied Technology Council, and others include damage analysis at a highly detailed level, requiring the compilation of fragility functions for a large number of damageable generic structural and nonstructural components. This brief paper presents the development of a fragility function for hydraulic elevators. It uses post-earthquake survey data from 91 elevators in nine California locations after two earthquakes. Surveys were used to collect data on facilities and elevators. Ground-motion records from the California Integrated Seismic Network were used to estimate engineering demands at each site. Binary regression analysis was used to fit a fragility function, which takes the form of a lognormal cumulative distribution function with median value of $P G A$ $=0.42 \mathrm{~g}$ and logarithmic standard deviation of 0.3 . The fragility function appears to be reasonable based on four criteria. [DOI: 10.1193/1.2720902]

\section{INTRODUCTION}

An important aspect of the second-generation performance-based earthquake engineering (PBEE-2) methodology developed by the Pacific Earthquake Engineering Research (PEER) Center (e.g., Porter 2003), the Applied Technology Council (2005), and others is the need for probabilistic relationships between component damage and engineering demands. These relationships are called fragility functions. They often take the form

$$
P[D M \geq d m \mid E D P=x]=\Phi\left(\frac{\ln \left(x / x_{m}\right)}{\beta}\right)
$$

where $P[D M \geq d m \mid E D P=x]$ denotes the probability that a component will reach or exceed some particular damage state, $d m$, given that the component was exposed to an engineering demand parameter (EDP) whose value is $x$. On the right side of the equation, $\Phi$ denotes the cumulative standard normal (Gaussian) distribution function-an $\mathrm{S}$-shaped curve whose first derivative is a familiar bell-shaped curve. The terms $x_{m}$ and $\beta$ are parameters of the distribution and determine its shape. More details about the

\footnotetext{
a) California Institute of Technology, Pasadena, CA 91125-4400
} 
meaning, use, and creation of fragility functions for PBEE are presented in Porter et al. (2007).

The lognormal fragility function is used here for several reasons:

1. The lognormal fits a variety of seismic failure data well. Examples include reinforced concrete flexural members and connections (Beck et al. 2002, Aslani 2005, Pagni and Lowes 2006), suspended ceilings (Badillo-Almaraz et al. 2006), metal stud framed gypsum wallboard partitions (Porter and Kiremidjian 2001), building-service equipment (Reed et al. 1991 [Appendix J]), and estimated building collapse by IDA (e.g., Cornell et al. 2005).

2. It has strong precedent in seismic risk analysis, both for energy facilities (e.g., Kennedy and Short 1994, Nuclear Energy Agency Committee on The Safety of Nuclear Installations 1998) and ordinary buildings (e.g., Kircher et al. 1997). The Applied Technology Council (2005) intends to use the lognormal fragility function for most if not all damage analysis in its ATC-58 effort to bring PBEE-2 to professional practice.

3. There is a strong theoretical reason as well: the lognormal distribution has zero probability density at and below zero EDP, is fully defined by measures of the first and second moments (here, $x_{m}$ and $\beta$ ) and imposes the least assumed information given these constraints, in the information-theory sense of Shannon (1948).

There is a wide variety of damageable building components but relatively few fragility functions of the form needed to apply the PEER methodology in practice. For the methodology to be useful in the long term, numerous fragility functions must be developed for generic categories of structural and nonstructural components. Optimally, these fragility functions should be peer reviewed to assure quality and documented in archival journals to assure availability.

As part of a PEER study to estimate the future economic and life-safety seismic performance of a 2003 code-conforming reinforced concrete moment-frame building, it was necessary to create a new fragility function for hydraulic elevators. This technical note addresses the creation of such a fragility function from available literature.

To begin the analysis, primary sources were reviewed to quantify the number of specimens observed, their age, installation conditions, manufacturer, the number and nature of specimen damage, the location of each specimen, and the earthquake to which they were subjected. To estimate the seismic excitation at each specimen location, the specimen was geolocated by street address using Microsoft Streets and Trips (2003). Two nearby strong-motion instruments were found using CISN (2003a and 2003b). The distance between the specimens and each nearby instrument was calculated using spherical geometry. The peak ground acceleration (PGA) at each strong-motion instrument was noted, and the PGA at the site of the specimen was estimated as a weighted average of the PGAs at the two nearby strong-motion instruments, with weights inversely proportional to distance. Although in PEER terminology PGA is usually considered an intensity measure (IM), in the case of equipment located at or near the ground floor it can be used as an EDP, the typical input to a fragility function. (Conceivably, damage might 
just as well have been correlated with the spectral accelerations, spectral displacements, or interstory drifts to which they were exposed, but for most of the specimens, the data sources examined here provided too little structural information to assess these parameters.)

Site soil at all three locations - that of the specimen and the two nearby strongmotion instruments - was determined in terms of NEHRP site-soil category from the map by Wills et al. (2000). Where soil conditions do not differ by one NEHRP category, no adjustment was made for differing site soils. For example, no adjustment was made to correct for CD versus D soil category.

\section{SPECIMENS, EXCITATION, AND DAMAGE EVIDENCE}

Extensive data are available regarding the performance of traction elevators. For example, Yao (2001) discusses damage to traction elevators in the 1999 Chi-Chi earthquake. Suarez and Singh (2000) present a review of code development and past seismic performance of traction elevators. Levy et al. (2000) review the performance of traction elevators in the 1995 Gulf of Eilat-Aqaba earthquake, with emphasis on the design of rails. Schiff (1988) reports on a telephone survey of municipal elevator departments and elevator companies after the 1987 Whittier Narrows earthquake, and presents general trends.

By contrast, relatively little data are available on the performance of hydraulic elevators. Kao et al. (1999) represents a valuable resource for beginning any study of the seismic performance of nonstructural building components. It records 2,900 instances of damage to nonstructural components, drawn from a literature review of 103 books, reports, and periodicals about 52 earthquakes between the 1964 Anchorage, Alaska earthquake and the 1999 Quindio, Colombia earthquake.

The Kao et al. (1999) database contains approximately 237 records that relate to the seismic performance of elevators. One can often distinguish whether an elevator is hydraulic or traction by examining the damage description. The word "hydraulic" appears in damage descriptions for 20 records, describing elevators at five facilities, and referring to two primary sources: Schiff (EERI 1990) and Finley et al. (1996). These sources were examined for information about the total number of elevators exposed to damage (as opposed to the number damaged) and other details such as year installed and building location.

Schiff (EERI 1990) provides information about the seismic performance of elevators at Stanford University in the 1989 Loma Prieta earthquake. At that time, the campus had 77 hydraulic elevators, of which four were damaged. In two elevators, "Controls were damaged. Dust covers on electrical boxes came loose and fell to the top of the car, damaging vane and hoistway switches." In one, "Water damaged [the] hoistway and car control of a hydraulic elevator. Damage had to be repaired before the elevator could be put back into service." In one elevator, "A hydraulic elevator entrance and car door were damaged." In one, "Vibrations caused an oil leak in a hydraulic line at a threaded connection." In at least two instances, "There was damage to the entrance to a hydraulic elevator hoistway." These sum to more than four, which suggests that some damaged el- 
Table 1. Estimated PGA at elevator sites

\begin{tabular}{lcccccc}
\hline \hline Location & $\varphi$ (N lat) & $\lambda($ E lon) & Soil & PGA (g) & Dist $(\mathrm{km})$ & Dir \\
\hline Stanford University & 37.43 & -122.17 & CD & 0.26 & & \\
$\quad$ XSPG & 37.43 & -122.17 & CD & 0.26 & $<1.0$ & NE \\
SLAC & 37.42 & -122.20 & C & 0.29 & 3.3 & SE \\
Valley Presbyterian & 34.19 & -118.46 & D & 0.38 & & \\
NHW & 34.19 & -118.41 & D & 0.32 & 3.3 & SE \\
NRG & 34.21 & -118.52 & D & 0.45 & 4.6 & NW \\
St. Johns Hospital & 34.03 & -118.48 & CD & 0.50 & & \\
LPU & 34.04 & -118.44 & D & 0.52 & 2.8 & NE \\
MBS & 34.00 & -118.43 & CD & 0.47 & 4.7 & SE \\
Cedars-Sinai & 34.08 & -118.38 & D & 0.26 & & \\
HLC & 34.09 & -118.36 & D & 0.26 & 1.9 & NE \\
LCN & 34.06 & -118.42 & CD & 0.26 & 3.1 & SW \\
Northridge Medical Center & 34.22 & -118.53 & D & 0.45 & & \\
NRG & 34.21 & -118.52 & D & 0.45 & 1.5 & SE \\
CPC & 34.21 & -118.61 & D & 0.41 & 6.3 & SW \\
USC Medical Center & 34.06 & -118.21 & CD & 0.25 & & \\
$\quad$ LTH & 34.06 & -118.25 & CD & 0.18 & 1.9 & NW \\
LCI & 34.05 & -118.17 & CD & 0.32 & 1.8 & SE \\
\hline \hline
\end{tabular}

* PGA at elevator sites is the weighted average PGA of the two nearby instruments shown

evators had more than one of these symptoms. No information on code era, framing system, building height, building period, or other building information is available for any of the specimens.

See Table 1 for the location, PGA estimate, and NEHRP site-soil category at Stanford University (the location shown is that of the Memorial Church) and at the locations of nearby strong-motion instruments and other facilities examined here. In the table, the first column shows locations where elevators were examined as well as the identifiers of nearby strong-motion instruments. The second and third columns give the latitude and longitude of the elevators or nearby instruments. The fourth column gives the NEHRP site class estimated by Wills et al. (2000). The last three columns give the estimated peak ground acceleration at the elevator location, and the observed PGA at the nearby strongmotion instruments, as well as the distance and direction from the elevator location to the strong-motion instruments.

Finley et al. (1996) performed a detailed survey of hydraulic elevators in nine Los Angeles-area hospitals after the 1994 Northridge earthquake, on behalf of the California Office of Statewide Health Planning and Development (OSHPD). The survey examined 100 traction elevators and 14 hydraulic elevators. Only the hydraulic ones are discussed here. Damage states of interest include failure of equipment anchorage; damage to car guide shoes, cab stabilizers, cab interior, snagged ropes and traveling cables; and failure of hydraulic cylinder or piping. Other damage states examined by Finley et al. (1996) are ignored, including loss of building power or damage to the hoistway walls or sprinkler 
pipes. Note that Finley et al. (1996) believed that elevator manufacturers and installation dates might be material to understanding damage, as did Schiff (personal communication with the author, 2006), so these data are repeated here for later reference.

Valley Presbyterian Hospital had four hydraulic elevators (numbers seven through ten). Elevator seven was manufactured by Montgomery and installed in 1983. It had two stops. Elevators eight, nine, and ten were manufactured by Montgomery and installed in 1985 (these had three stops). The building is reported variously as "Concrete Steel w/ Drywall" and "Concrete." Of the four elevators, cab stabilizers were bent in elevators nine and ten. Number ten also had snagged ropes or traveling cables. The facility was located at 15107 Van Owen St., Van Nuys, CA 91405.

Three buildings at St. Johns Hospital had hydraulic elevators. The main wing had one hydraulic elevator (the kitchen freight elevator), manufactured by Otis and installed at an unknown date. It had two stops. The elevator's hydraulic tank failed, and flooring in the cab was damaged. The main wing is recorded as being reinforced masonry, but it appears from photographs to be reinforced concrete (as is more likely, considering that at least a part of building had a seven-stop traction elevator). The south wing likewise had one hydraulic elevator (the freight elevator), manufactured by Otis and installed in 1965. It had two stops. The elevator's hydraulic tank failed, and flooring in the cab was damaged. The south wing appears to have been of reinforced concrete construction. The Mental Heath Center had two hydraulic elevators (elevators one and two), manufactured by Elevator Maintenance and installed in 1966; these had five stops. In both elevators, the car guide shoes were damaged. The building is reported to be of concrete construction. The hospital was located at 1329 22nd St., Santa Monica, CA 90404.

Cedars-Sinai Becker Building had one hydraulic elevator (elevator one), built by Otis and installed in 1988. It was installed in a steel-frame building, and had two stops. It was undamaged. The Cedars-Sinai Thalians Cancer Building had two hydraulic elevators (numbers one and two), manufactured by Otis and installed in 1986. They had three stops. The elevators suffered no damage. Cedars-Sinai Medical Center is a steel-frame building located at 8700 Beverly Blvd., Los Angeles, CA 90048.

Northridge Medical Center Gellespie Institute for Living had two hydraulic elevators (one and two), manufactured by Amtech and installed in 1976. They had five stops and were installed in a steel-frame building. Damage included one hydraulic-cylinder failure requiring replacement. The facility was located at 18300 Roscoe Blvd., Northridge, CA 91328.

USC Medical Center had one hydraulic elevator (called simply Hydro), unknown manufacturer, 1971 installation, two stops, concrete frame with reinforced masonry (infill, perhaps), and no damage. The building is located at 1200 N. State St., Los Angeles, CA 90033.

Table 2 summarizes the number of specimens, estimated PGA to which each was subjected, number of hydraulic elevators at the location, and number damaged. Table 3 summarizes the recorded modes of damage. The table shows the number of instances of each mode of damage, and the estimated conditional probability that, if damaged, an el- 
Table 2. Summary of hydraulic elevator failure data

\begin{tabular}{lcccc}
\hline \hline Location & $\begin{array}{c}\text { PGA } \\
(\mathrm{g})\end{array}$ & $\begin{array}{c}\text { No. } \\
\text { Exposed }\end{array}$ & $\begin{array}{c}\text { No. } \\
\text { Damaged }\end{array}$ & Earthquake \\
\hline Stanford University & 0.26 & 77 & 4 & Loma Prieta \\
Valley Presbyterian & 0.38 & 4 & 2 & Northridge \\
St. Johns Hospital Main Wing & 0.50 & 1 & 1 & Northridge \\
St. Johns Hospital South Wing & 0.50 & 1 & 0 & Northridge \\
St. Johns Hospital Mental Health Center & 0.50 & 2 & 2 & Northridge \\
Cedars-Sinai Becker & 0.26 & 1 & 0 & Northridge \\
Cedars-Sinai Cancer & 0.26 & 2 & 0 & Northridge \\
Northridge Medical Center & 0.45 & 2 & 1 & Northridge \\
USC Medical Center & 0.25 & 1 & 0 & Northridge \\
Total & & 91 & 10 & \\
\hline \hline
\end{tabular}

evator is damaged in that particular way. The conditional probabilities sum to more than 1.0 because some elevators experienced damage in more than one way.

\section{CALCULATION OF FRAGILITY FUNCTION}

The data shown in Table 2 were analyzed to create a fragility function using binary regression analysis, as follows. The engineering demand parameter (EDP) of interest is the estimated peak horizontal ground acceleration (PGA) at the site. Each elevator was treated as a single specimen with an $\mathrm{x}$-value equal to PGA, and a y-value of 1 if it failed or 0 if it did not. Failure is defined here as any of the damage modes selected from EERI (1990) or Finley et al. (1996), as discussed above. A lognormal cumulative distribution

Table 3. Summary of seismic damage modes for hydraulic elevators

\begin{tabular}{lcc}
\hline \hline Mode of Damage & Instances & Conditional Probability \\
\hline Damaged controls & 3 & 0.3 \\
Damaged vane and hoistway switches & 2 & 0.2 \\
Damaged entrance and car door & 3 & 0.3 \\
Oil leak in hydraulic line & 1 & 0.1 \\
Bent cab stabilizers & 2 & 0.2 \\
Snagged ropes or traveling cables & 1 & 0.1 \\
Hydraulic tank failure & 3 & 0.3 \\
Flooring damage & 2 & 0.2 \\
Damaged car guide shoes & 2 & 0.2 \\
\hline \hline
\end{tabular}


function was fit to the data by minimizing the sum of the squared differences between the data and the cumulative distribution function. That is, let

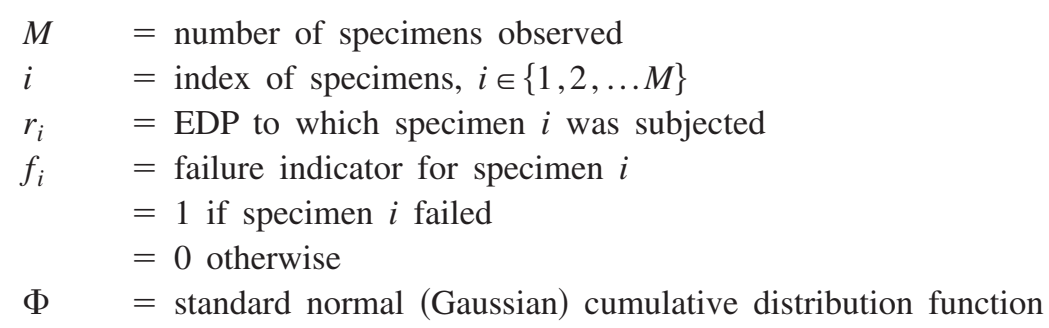

The fragility function parameters $x_{m}$ and $\beta$ were found by minimizing the average squared error $\epsilon^{2}$ such that:

$$
\varepsilon^{2}=\frac{1}{M} \sum_{i=1}^{M}\left(f_{i}-\Phi\left(\frac{\ln \left(r_{i} / x_{m}\right)}{\beta}\right)\right)^{2} x_{m}>0 \beta>0
$$

\section{RESULTS}

The resulting lognormal fragility function has median value $x_{m}=0.41 \mathrm{~g}$ and logarithmic standard deviation $\beta=0.28$. As a check, the analysis was performed again on a facility-by-facility basis, weighting each of the facilities examined here equally. The failure rate at each facility was calculated as the number of failed elevators divided by the number of elevators exposed to damage. These failure rates were plotted against PGA, and the lognormal CDF was fit to these data. The result is a fragility function with $x_{m}=0.42 \mathrm{~g}$ and $\beta=0.29$, essentially identical to the result from binary regression analysis. (Note that the binary regression analysis is preferred; weighting each facility equally would be inappropriate, given that Stanford University had 77 of the 91 specimens.)

Figure 1 shows the facility-by-facility failure rates and the fragility function fit by binary regression analysis. Despite the difference in the analysis methods, the fragility function reasonably fits the data from the alternative approach.

Note that the data reflected in the fragility function come from both hospital elevators and non-hospital elevators. Schiff (personal communication with the author, 2006) advises that installation and other requirements for elevators in hospitals differ from non-hospitals. The implication is that a fragility function for the former is not necessarily appropriate for the latter. However, lacking better information to distinguish the fragility of elevators in the two categories of facility, a single function may be the best that can be achieved. Furthermore, since the Stanford data do not lie far from the hospital data, it may be reasonable to use a single fragility function.

\section{FRAGILITY FUNCTION QUALITY}

The category of data analyzed here are referred to in Porter et al. (2007) as bounding EDP (category B for bounding), in which some specimens failed and the maximum EDP 


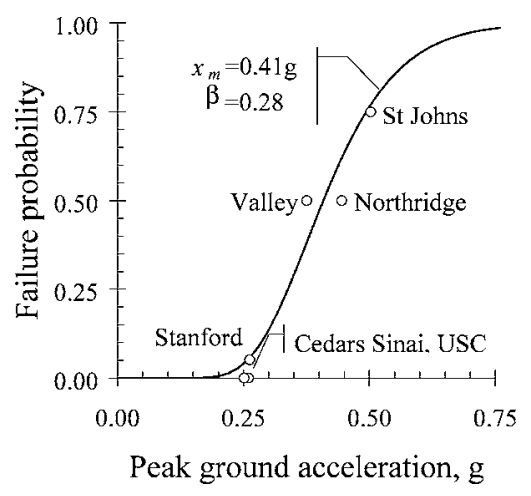

Figure 1. Fragility function fit to hydraulic elevator damage at Stanford University in the 1989 Loma Prieta Earthquake and at five hospitals in the 1994 Northridge Earthquake. The fragility function (a lognormal cumulative distribution function, with parameters shown) was fit using binary regression to 91 data pairs (EDP, failure).

to which each specimen was subjected is known. One can examine the quality of such a fragility function by considering four features: (1) whether the value of the logarithmic standard deviation lies within the (typically observed) range of 0.3 to 0.6 ; (2) how well established is the 10th percentile failure EDP (i.e., the value of EDP at which the fragility function indicates $10 \%$ failure probability); (3) how many specimens were employed to establish the fragility function; and (4) how robust the fragility function is to the analysis method.

Comparing $\boldsymbol{\beta}$ with past experience. Kennedy and Short (1994) find that the logarithmic standard deviation $(\beta)$ of a fragility function for nonstructural components located near the ground floor tends to range between 0.3 and 0.5 ; at upper stories, $\beta$ is typically between 0.4 and 0.6 . If the $\beta$ for a new fragility function lies outside of this range ( 0.3 to 0.6$)$, it is questionable and should probably be examined more closely. In the present case, $\beta=0.3$, a reasonable result by this standard.

The 10th percentile EDP. This number is relevant because it speaks to the robustness of the fragility function. Kennedy and Short (1994) and Kennedy (1999) show that, if one establishes well the EDP at which the component has $10 \%$ failure probability, the overall reliability of the component is fairly insensitive to $\beta$, since a component is far more likely to experience excitation near lower fractiles such as the 10th percentile than at upper fractiles such as the 90th. (A related point: although the fragility function gives failure probabilities at higher values of EDP than appear in the data-here, $0.5 \mathrm{~g}$-any error resulting from that extrapolation has relatively little impact on overall reliability.) In the present case, the EDP near 10\% failure probability is fairly well established by the Stanford data: 77 specimens of which four failed, suggesting 5\% failure probability. With $\beta=0.3$, the 5 th percentile is close to the 10 th (differing by a factor of 1.15 ); since the bulk of the data lie near this EDP, the fragility function appears to be defensible on this point. 
Number of specimens. Ninety-one specimens comprise a relatively large sample as fragility functions go, comparable to the number of specimens for broad categories of standard industrial equipment in the EQE/EPRI seismic experience database (Swan and Kassawara 1998). Many other empirical fragility functions involve fewer than 25 specimens.

Robustness to analysis method. Finally, the fragility function has essentially the same parameters whether the regression analysis is performed on a binary (elevator-byelevator) basis or by fitting a curve to the per-facility failure rates.

Considering these four tests-reasonable $\beta, 10$ th percentile EDP, number of specimens, and robustness to analysis method - the fragility function seems defensible.

\section{CONCLUSIONS}

Second-generation performance-based earthquake engineering (PBEE-2) methodologies such as that of PEER or ATC-58 (ATC 2005) require fragility functions for all important damageable building components. These fragility functions are generic, and can be archived and applied to similar components in future analyses.

A fragility function relating hydraulic elevator damage to PGA was created. It was derived from survey data of 91 hydraulic elevators in nine locations. The damage state of interest includes any of the following: damage to controls, the elevator entrance, the car door, car guide shoes, cab stabilizers, cab interior, equipment anchorage, hydraulic cylinder or piping, or snagged ropes and traveling cables. A regression analysis was used to fit a lognormal cumulative distribution function to data that comprised 91 pairs of PGA and a failure indicator ( 1 if the elevator exceeded the damage state of interest, 0 otherwise). The resulting fragility function has a median value of $0.41 \mathrm{~g}$ and a logarithmic standard deviation of 0.3 .

The fragility function appears to be reasonable considering four tests: (1) the logarithmic standard deviation $\beta$ lies within the range of past experience; (2) the fragility function's 10th percentile (the EDP at which there is an estimated $10 \%$ failure probability, an important value for overall component reliability) lies close to most of the data; (3) a count of 91 specimens is a large number compared with other fragility functions; and (4) the results are robust to the analysis method.

\section{ACKNOWLEDGMENTS}

This work was supported primarily by the Earthquake Engineering Research Centers Program of the National Science Foundation, under award number EEC-9701568 through the Pacific Earthquake Engineering Research Center (PEER). Any opinions, findings, and conclusions or recommendations expressed in this material are those of the author and do not necessarily reflect those of the National Science Foundation. Thanks also to Anshel Schiff for information about differences between elevators in hospitals and those in other facilities. 


\section{REFERENCES}

Applied Technology Council (ATC), 2005. Guidelines for Seismic Performance Assessment of Buildings, 25\% Complete Draft, Prepared for the Department of Homeland Security, Washington, D.C.

Aslani, H., 2005. Probabilistic Earthquake Loss Estimation and Loss Disaggregation in Buildings, Ph.D. Thesis, Stanford University, Stanford, CA.

Badillo-Almaraz, H., Whittaker, A. S., Reinhorn, A. M., and Cimellaro, G. P., 2006. Seismic Fragility of Suspended Ceiling Systems, Technical Report MCEER-06-0001, Multidisciplinary Center for Earthquake Engineering Research, Buffalo, NY.

Beck, J. L., Porter, K. A., Shaikhutdinov, R., Au, S. K., Mizukoshi, K., Miyamura, M., Ishida, H., Moroi, T., Tsukada, Y., and Masuda, M., 2002. Impact of Seismic Risk on Lifetime Property Values, Final Report, Consortium of Universities for Research in Earthquake Engineering, Richmond, CA [also at: http://resolver.caltech.edu/caltechEERL:2002.EERL2002-04, viewed 05 May 2006].

California Integrated Seismic Network (CISN), 2003a. CISN peak accel. map (in \% g) for Loma Prieta Earthquake, CISN ShakeMap, available at: http://www.cisn.org/shakemap/nc/ shake/LomaPrieta/pga.html [viewed 05 May 2006].

— 2003b. CISN peak accel. map (in \% g) for Northridge Earthquake, CISN ShakeMap, available at: http://www.cisn.org/shakemap/sc/shake/Northridge/pga.html [viewed 05 May 2006].

Cornell, C. A., Zareian, F., Krawinkler, H., and Miranda, E., 2005. Prediction of probability of collapse, in Van Nuys Hotel Building Testbed Report: Exercising Seismic Performance Assessment, Report 2005-11, edited by H. Krawinkler, Pacific Earthquake Engineering Research Center, Richmond, CA, pp. 85-93.

Earthquake Engineering Research Institute (EERI), 1990. Loma Prieta Earthquake reconnaissance report, Earthquake Spectra 6 (S1).

Finley, J., Anderson, D., and Kwon, L., 1996. Report on the Northridge Earthquake Impacts to Hospital Elevators, Contract No. 94-5122, California Office of Statewide Health Planning and Development (OSHPD), Sacramento.

Kao, A., Soong, T. T., and Vender, A., 1999. Nonstructural Damage Database, MCEER-990014, Multidisciplinary Center for Earthquake Engineering Research, State University of New York, Buffalo.

Kennedy, R. P., 1999. Overview of methods for seismic PRA and margin analysis including recent innovations, Proceedings, OECD-NEA Workshop on Seismic Risk, Tokyo, Japan.

Kennedy, R. P., and Short, S. A., 1994. Basis for Seismic Provisions of DOE-STD-1020, UCRLCR-111478, U.S. Dept. of Energy, Washington, D.C.

Kircher, C. A., Nassar, A. A., Kustu, O., and Holmes, W. T., 1997. Development of building damage functions for earthquake loss estimation, Earthquake Spectra 13, 663-682.

Levy, R., Rutenberg, A., Magnus, P., Marianchik, E., and Segal, F., 2000. Performance of elevator systems in the 22 November 1995 Gulf of Eilat-Aqaba Earthquake, Earthquake Spectra 16, 607-619.

Microsoft Corporation, 2004. Microsoft Streets and Trips (version 12.00.07.1200), Microsoft Corporation, Redmond, WA.

Pagni, C. A., and Lowes, L. N., 2006. Fragility functions for older reinforced concrete beamcolumn joints, Earthquake Spectra 22, 215-238. 
Porter, K. A., 2003. An overview of PEER's performance-based earthquake engineering methodology, Proceedings, Ninth International Conference on Applications of Statistics and Probability in Civil Engineering (ICASP9), San Francisco, CA, Civil Engineering Risk and Reliability Association (CERRA), 973-980 [also at: http://keithp.caltech.edu/ publications.htm, viewed 05 May 2006].

Porter, K., Kennedy, R., and Bachman, R., 2007. Creating fragility functions for performancebased earthquake engineering, Earthquake Spectra 23, 471-489.

Porter, K. A., and Kiremidjian, A. S., 2001. Assembly-Based Vulnerability and its Uses in Seismic Performance Evaluation and Risk-Management Decision-Making, Report No. 139, John A. Blume Earthquake Engineering Center, Stanford, CA [also at: http://keithp.caltech.edu/ publications.htm, viewed 05 May 2006].

Reed, J. W., Kennedy, R. P., Buttemer, D. R., Idriss, I. M., Moore, D. P., Barr, T., Wooten, K. D., and Smith, J. E., 1991. A Methodology for Assessment of Nuclear Power Plant Seismic Margin (Revision 1), NP-6041-SL Revision 1, Research Project 2722-23, Electric Power Research Institute, Jack R. Benjamin and Associates, Inc., Mountain View, CA.

Schiff, A. J., 1988. The Whittier Narrows, California Earthquake of October 1, 1987-response of elevators, Earthquake Spectra 4, 367-375.

Shannon, C. E., 1948. The mathematical theory of communication, Bell Syst. Tech. J. 27, 379423, 623-656 [also at: http://cm.bell-labs.com/cm/ms/what/shannonday/shannon1948.pdf, viewed 20 September 2006].

Suarez, L. E., and Singh, M. P., 2000. Review of earthquake performance, seismic codes, and dynamic analysis of elevators, Earthquake Spectra 20, 853-878.

Swan, S. W., and Kassawara, R., 1998. The use of earthquake experience data for estimates of the seismic fragility of standard industrial equipment, ATC 29-1, Proceedings, Seminar on Seismic Design, Retrofit, and Performance of Nonstructural Components, Applied Technology Council, Redwood City, CA, pp. 313-322.

Wills, C. J., Petersen, M., Bryant, W. A., Reichle, M., Saucedo, G. J., Tan, S., Taylor, G., and Treiman, J., 2000. A Site Conditions Map for California Based on Geology and Shear Wave Velocity, California Geological Survey, Sacramento.

Yao, G. C., 2001. Seismic performance of passenger elevators in Taiwan, Earthquake Eng. Eng. Seismology 3, 17-26.

(Received 8 May 2006; accepted 4 October 2006) 